\title{
Information and communication technologies in teaching foreign languages
}

\author{
Natalia Gorokhova ${ }^{1, *}$, and Irina Kubyshko ${ }^{2}$ \\ ${ }^{1}$ Gubkin Russian State University of Oil and Gas (National Research University), Moscow, Russia \\ ${ }^{2}$ Moscow City University, Moscow, Russia
}

\begin{abstract}
The introduction of information and communication technologies in the modern educational process at all levels is widespread in the world. The algorithm of successful e-learning, peculiarities of using online formats as one of the ways of educational resource of foreign language teaching, criteria of platforms, and applications selection constitute the study's relevance and its main goal. The author proposes a methodology of teaching a foreign language based on the use of technical means of information and communication technologies, its methodologically secured system of electronic ways of monitoring, control, evaluation, and the classification of online tools aimed at building the educational process. The described analysis of the foreign language teaching process based on the application of information and communication technologies is of scientific and pedagogical interest from educational information transmission in a non-linear format. The results obtained in the study can be useful for teachers in the implementation of the general management of cognitive activity of students, in communicative and advisory activities, holding mono-courses or collective projects developed by educational organizations.
\end{abstract}

\section{Introduction}

One of the most relevant studies of online platforms of an educational resource for improving the learning process based on modern technology is due to the transition to the new competency-based paradigm of education. Online education accounts for $1.1 \%$ (about 21 billion rubles) of the total education market in Russia [15]. The new system's capabilities allow solving the problems of building an individual educational trajectory and additional professional training of a student, forming his/her ability to self-organization and selfeducation [14]. The development of the Russian digital education space is aimed at increasing accessibility of education in general [3], the implementation of the concept of lifelong learning [6], the use of modern information and communication technologies by educational organizations as the main trend of online education [8] - all the above is the object of interest of the Russian Federation, seeking to increase its presence in the said segment of the educational services market, as evidenced by the implementation of the priority project for 2016 [14]. Modern education, striving to find an algorithm for successful e-learning, aims at using online formats as one of the ways of educational resource of learning [2]. Currently,

\footnotetext{
* Corresponding author: n.gorokhova@nxt.ru
} 
the use of technical means of information and communication technologies is the object of study not only by linguists when teaching a foreign language but also by scientists from different fields of knowledge $[1,9,11,16,25]$. The study of information and communication technology tools and the search for a methodologically sound system of electronic ways of the educational process allow considering online education as a potential source of new pedagogical approaches of e-learning. The pedagogical phenomenon aimed at using network learning technologies, electronic and interactive technologies provides an opportunity for significant transformation and transformation of educational programs.

\subsection{Investigation project}

The article focuses on using electronic online formats as one of the types of educational resources for foreign language teaching. The study was conducted from March 2020 to March 2021 as part of a larger program to develop pedagogical technologies and innovative trends in online education. The program was launched in 2020 to create the necessary prerequisites for forming a modern digital educational environment and aims to increase the accessibility of education and implement the concept of lifelong learning through the development of the Russian digital educational space [13]. A key component of the program is coordination between experts in technical fields on the one hand and linguists in a foreign language on the other. The project, in turn, involves a significant number of professional philologists and technicians, most of whom are university professors. Due to the nature of such work, foreign language teaching methodology built on the application of technical means of information and communication technologies was formed, a methodologically supported system of electronic ways of observation, control, and evaluation was developed, as well as a classification of online tools for building the educational process, to serve the actively growing trend of digitalization of the educational environment $[2,4,5,19,20]$.

\subsection{Definition of terminology}

The most common meanings of the term "information and communication technologies" can be found in different sources; most of them represent them as a set of methods, mechanisms, and tools used for automated collection, processing, storage, and transmission of information [2]; a set of methods, devices and production processes used by society to collect, store, process and transmit information [10]; mastering the technology of working in an integrated multimedia environment, implementing the further development of the idea of associatively related information received, processed and presented in various forms, taking into account the psychological and pedagogical foundations of using technical means [18]; the integration of telecommunications (telephone lines and wireless signals) and computers, as well as the necessary corporate software, middleware, storage systems and audio-visual systems that allow users to access, store, transmit and manipulate information [12]. The modern stage in the development of information and communication technologies is characterized by their powerful influence on all processes and spheres of human activity, providing instantaneous distribution of information, forming a global information space, actively penetrating and optimizing the functioning of science, education, culture, politics, as well as economic and national security.

Application of information and communication technologies in pedagogical practice is carried out based on computing devices and telecommunication systems that provide access to information resources and are divided into the following categories: training; simulators; information retrieval and reference; demonstration; simulation; laboratory; simulation; calculation; training and game tools [7]. The global information space involves the use of multiple principles of technology classification. One of the basic types of information and 
communication technology systematization includes typing by subject activities, but in the educational environment, information and communication technology is divided into the following types:

Software products that ensure the quality of design and ergonomics (programs to prepare for classes, lectures, seminars);

Special technologies through which material is searched for and transferred;

Telecommunication technologies ensuring communication between participants of the educational process [22].

The typology of platforms and applications actively used in the educational process of teaching foreign languages can be represented as a diagram (Fig. 1)

Self-test simulator tests
Templates, Wor visualizing materials and for creating mind maps
•Padlet, Miro, Mindmeister, My Simple Show
Social media storage
•YouTube, Audacity, Podomatic
Templates for creating search-problem tasks
•Zunal
Services for creating questionnaires and survey forms
• SurveyMonkey, Google Forms
Learning Management Systems (LMS)
•Moodle, Blackboard, Canvas, Google Classroom, Edmodo

Fig. 1. Typology of foreign language learning platforms and applications.

The diversity of modern learning platforms and applications determines the needs of the pedagogical community for computerization and informatization of the education system. The basic information and communication technology skills that one acquires during training are not only applied in one's professional life but also in everyday life. Today's education system requires the active introduction of computerized tools, allowing to use of qualitatively new possibilities of the educational process, which brings teaching and learning to a higher level. The criteria for selecting electronic platforms to design online foreign language courses are presented in the diagram (Fig. 2).
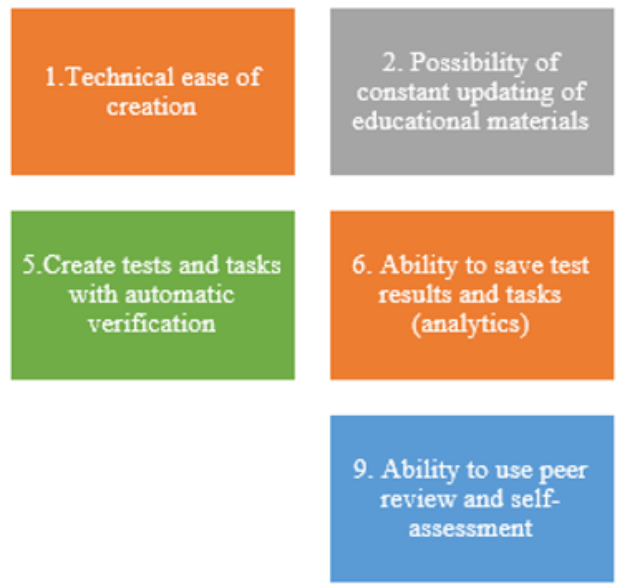

4. Prompt feedback (video conferencing, chats, forums, voting)
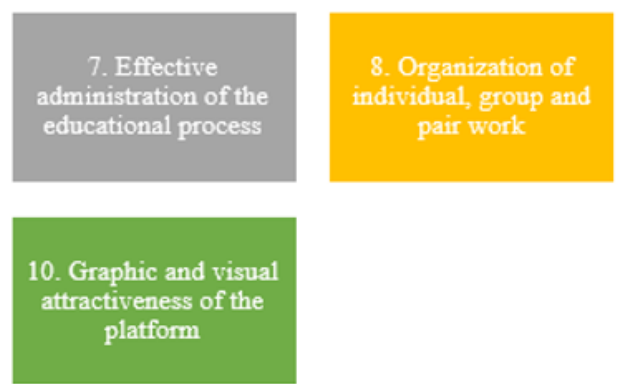

Fig. 2. Selection criteria for online platforms.

The proposed gradation of the criteria is not exhaustive or conclusive. E-course is a pedagogical phenomenon in relation to which pedagogical theory builds its practical 
application. New methods, approaches, and technologies are sometimes formed before the educational community understands what is happening. Nowadays, every teacher has access to the possibilities offered by technical resources. Among the large number of tools, three groups can be distinguished:

Exploring and using information from the Internet: e-textbooks, specialized educational websites, reference books and dictionaries, practice software, etc.;

Interactive presentation and storage of information: presentations, broadcast video clips for multifaceted topic coverage, voice or video recording of lectures and seminars, instant distribution of material among students, etc.;

Distance education and types of communication: forums, webinars, chat rooms, online conferences, e-mail, etc. [23].

The listed tools provide not only rapid dissemination of information, continuous communication between students and teachers, which is very important for pedagogy and improving the efficiency of the learning process but also help to form a sustainable motivation in students, promote interest in the subject, activate students' abilities [1]. A new term "edutainment" (education + entertainment) appeared in scientific literature and represents a modern pedagogical innovation that is based on visual material, narration, modern psychological techniques, game format, information, and communication technologies, which aims at maximum facilitation of events analysis, maintenance of emotional connection with the object of learning, attraction and long-term retention of students' attention [16]. The main components included in digital content that combine educational and entertainment elements while keeping the audience informed and analyzing events as easily as possible are shown in the diagram (Fig. 3).

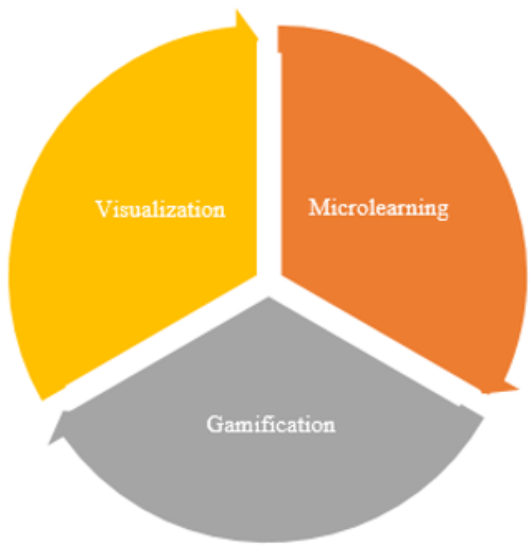

Fig. 3. Edutainment process.

\section{Research methods}

The methods of using information and communication technologies currently do not have a complete and correct basis in the educational process. The connection between the methodology of using information technologies in the educational space and teaching methodology as a generic concept possessing a supra-structural nature is obvious; the prerequisites for the emergence of a new science should be considered the allocation of its subject, the development of new concepts, solution of specific problems, development of an original apparatus. The methodology of using technology in the learning process is the science of the regularities of selecting and using pedagogical technologies, particularly information and communication technologies. Their means to achieve learning objectives 
based on the specific content of the educational discipline in different psycho-pedagogical situations [23]. Many researchers propose the definition of information and communication technology application methods in the educational process as a set of regularities (rules, principles, and laws) normalizing the choice of educational technologies or their means in certain conditions [2]; activity of designing, modeling, choosing and adapting to certain psychological and pedagogical conditions of a specific subject area [21]; projection of knowledge component into the space of objectives, specific psychological and pedagogical conditions and features set by the subject area [23]; educational technology aimed at achieving learning objectives on specific subject content in certain pedagogical situations [24].

The basic concepts defining the methods of using information and communication technologies in foreign language teaching are the invariant modules of the online course (Fig. 4).

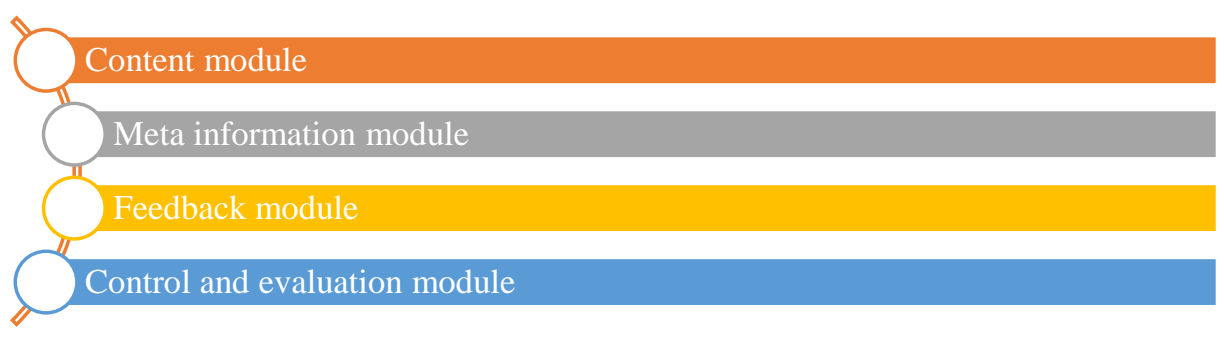

Fig. 4. Invariant modules of the online course.

The content module of foreign language teaching describes the proposed course of study, defines its goals and objectives; guides the search for teaching material (videos, graphs, presentations, podcasts, tables); creates glossaries or reference material; creates teachingthematic and calendar plans; shows examples of completed tasks, and presents the development of tests and control exercises. The meta-information module includes additional open educational resources (educational websites, online simulators, video services, scientific articles, tutorials, and reference resources (dictionaries, encyclopedias). The feedback module is built around the course via video conferencing, forums, comments, group chats, or private messages. This module uses additional feedback options such as email, mobile, social media, and messengers. The control and assessment module use assessment criteria for tasks (teacher's assessment, self-assessment, peer-assessment), operates with materials for knowledge control (current, interim, and final), and offers assessment scales.

\section{Findings}

A successful e-course using the online format as one of the ways of educational resource of foreign language teaching has certain criteria and characteristics, based on which the whole algorithm of e-pedagogical cycle development will be built in the future. The main parameters of online foreign language courses can be presented as a table (Table 1). 
Table 1. Criteria and characteristics of the online course.

\begin{tabular}{|c|c|c|c|}
\hline Criteria & individual & group & \\
\hline $\begin{array}{c}\text { Interaction of } \\
\text { learners }\end{array}$ & short & long term & \\
\hline $\begin{array}{c}\text { Duration of } \\
\text { training }\end{array}$ & synchronous & asynchronous & \\
\hline $\begin{array}{c}\text { Organization of } \\
\text { training }\end{array}$ & research project & $\begin{array}{c}\text { educational } \\
\text { course }\end{array}$ & educational course \\
\hline $\begin{array}{c}\text { The purpose of } \\
\text { training }\end{array}$ & open access course & $\begin{array}{c}\text { partially open } \\
\text { access course }\end{array}$ & closed access course \\
\hline $\begin{array}{c}\text { Access to the } \\
\text { course }\end{array}$ & professional course & amateur race & \\
\hline $\begin{array}{c}\text { Creation } \\
\text { technology }\end{array}$ & educational organization & private person & \\
\hline ISP & mass rate & small course & \\
\hline $\begin{array}{c}\text { Number of } \\
\text { students }\end{array}$ & full course & micro course & nano course \\
\hline Type of training & theoretical course & applied course & \\
\hline Learning content & \multicolumn{2}{|c|}{. }
\end{tabular}

The classification of criteria can also be made according to other parameters, so the proposed systematization is not comprehensive. In many cases, an additional characteristic of an educational resource in foreign language teaching is the number of teaching staff involved in the delivery of the e-cycle and the degree of their involvement and type of employment. The teacher can give lectures, act as a speaker or remain "behind the scenes"; provide general guidance for students' independent cognitive activity; communicate with listeners, advise them on academic issues in the course forum [14]. Teachers may work in tandem on one or more subject cycles that are content-related and thematically interrelated, with each teacher assigned to a specific section or discipline.

The algorithm for developing an online foreign language course, as well as the choice of online platforms and applications for its compilation, are not rigidly deterministic and rather varied. Still, the attempt to define the conditions for the effectiveness of the project makes it possible to highlight the main categories of such training (Fig. 4).

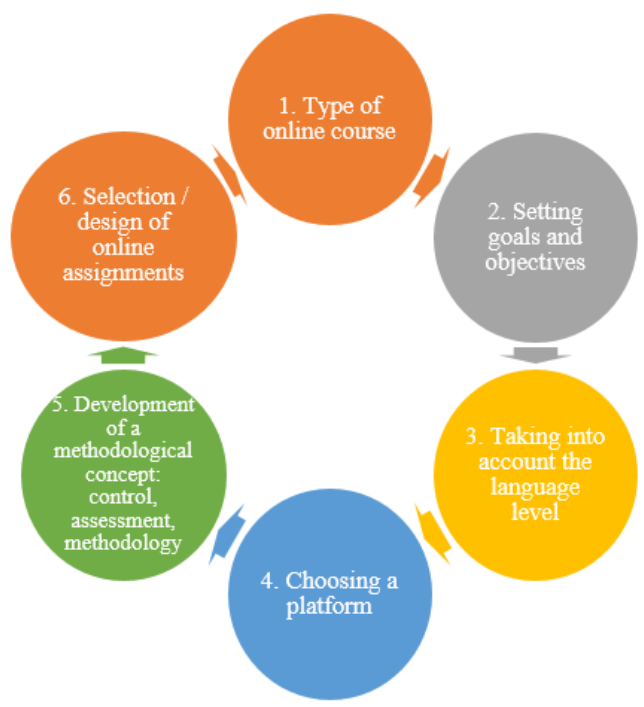

Fig. 4. The algorithm for developing an online course. 


\section{Results}

The algorithm of building an online foreign language course using information and communication technologies, the choice of remote platforms and applications as one of the ways of educational resource of learning, as well as the definition of criteria determining the successful e-learning, have determined the development of methodological techniques of applying technical means and online tools in the educational process. The formulation of methodological techniques is closely connected with the definition of the main didactic principles of distance interaction occurring in online mode at all stages of the learning process:

(a) Task setting - formulating the conditions of the learning process, its main stages, and elements, providing methodological guidelines, etc. At this stage, students learn how to consistently self-check and self-analyse their own results;

b) model setting - a type of learning activity which is demonstrated using one of the modeling tools (MS Visio, Google WatchUp, MathCad, MS Excel, etc.), here conditions of the experiment are formulated, hypotheses are put forward, confirmed, or disproved, students observe changes in their own computer model;

c) visual constructs serve to form an understanding of the essence of thinking operations and activities related to analysis, synthesis, generalization, classification, systematization, concretization, etc., as well as visual presentation and selection of material;

d) instructions or symbols used to connect different activities with learning information: formulating one's own point of view, reading, memorizing, analyzing, writing, solving tasks of increased difficulty, etc. [23].

The given set of techniques is not complex and final; it will be specified and changed depending on types of educational event, purposes of a lesson or task, psychological characteristics of students, etc. To organize successful online learning, content and a set of didactic and diagnostic materials should be provided, which will allow the use of simple tools or predesigned templates. The learner will be able to individually or collectively operate the specified resources at his or her convenience. Such resources include, for example, Google Docs, Prezi.com, Anketer.ru, Webanketa.com, Scorotest.ru, Learningapps.org, etc.

The above techniques allow us to formulate a conclusion about the pedagogical feasibility and didactic significance of using information and communication technologies in the transition to active computer-based methods of teaching students. The sum of these techniques is far from being complete, but it can probably serve as a general guideline for constructing a sequence of expedient learning situations.

\section{Conclusion}

The conducted research regarding the implementation of information and communication technologies in the modern educational process confirms that successful e-teaching, using online formats as one of the ways of educational resource of foreign language teaching, meets all the methodological and didactic objectives set for the system of computerized teaching techniques and digitalization of educational environment in general (Fig. 5). 


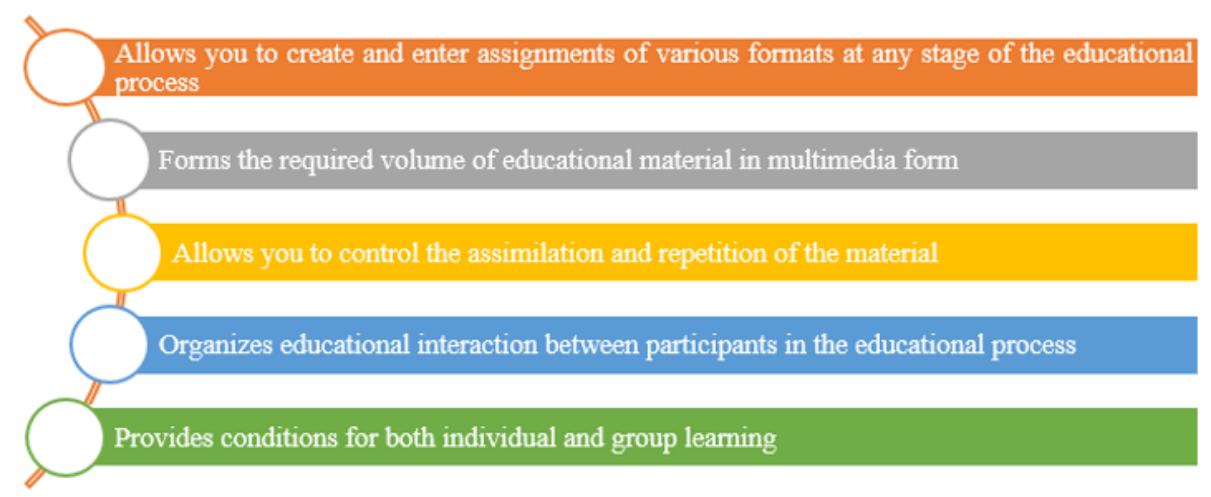

Fig. 5. Didactic objectives of online learning.

The categorization of electronic educational resources, elaboration of criteria for selecting electronic platforms for designing online foreign language courses, characterization of techniques and methods of distance learning sources made it possible to develop a basic algorithm for creating an effective online foreign language course, as well as to analyze the advantages governing the quality of teaching programs, to present the classification of open online tools and educational process tools. The study found that online platforms and apps have undeniable advantages, such as:

- visualization of teaching material;

- introduction of a gamification element of learning;

- introduction of a microlearning element;

- language development;

- increasing student motivation;

- self-study;

- use as a means of control.

The conducted analysis of the educational process of teaching a foreign language based on the application of information and communication technologies allowed us to conclude that the introduction of new forms of educational resources is given great attention in the modern education system, which should meet the current requirements of the time and make the training programs more effective. The understanding and ability to work with new information and communication media in education lead to qualitative changes in the learning process in general, the formation of open educational space, the implementation of the social orientation of educational resources, which, in turn, is a new vector in the development of the teaching field. The research results can be useful for teachers and education specialists in pedagogical work and didactic practice, for systematization and development of evaluation criteria for electronic educational resources, further developments on standardization of information and communication technologies, their application, and further use teaching of foreign languages.

\section{References}

1. N.V. Gorokhova, High technologies, basic research, economics 3(1), 80 (2011)

2. N.V. Gorokhova, Revista Espacios 39(20), 6 (2018)

3. Y.A. Vagramenko, G.Y. Yalamov, Information technologies and network resources in education (2015)

4. L.K. Zainutdinova, Theses of reports at Russian Conference: "University, spirit, honor, culture" (1995) 
5. V.I. Kirko, N.I. Pack, E.V. Malakhova, The Turkish Online Journal of Distance Education - TOJDE 15(4), 23 (2014)

6. I.V. Robert, Theory and methodology of informatization of education (psychological, pedagogical and technological aspects), 3rd edition (2010)

7. A.N. Afonin, Y.A. Vagramenko, Pedagogical Informatics 2, 25 (2017)

8. T.A. Lavina, Informatics and education 7, 105 (2006)

9. L.P. Martirosyan, Informatics and Education, 6 (2004)

10. I.V. Robert, Collection of articles of the International Scientific and Practical Conference "Information Technologies in Education" (2010)

11. I.S. Mukhametzyanov, Medical aspects of informatization Education: Monograph (2010)

12. I.I. Kosenko, Informatics and education, 9 (2008)

13. Passport of the priority project "Modern digital educational environment in the Russian Federation". http: //www.consultant.ru/document/cons_doc_LAW_216432 /

14. N.V. Grechushkina, Higher education in Russia 27(6), 125 (2018)

15. Research of the Russian market of online education and educational technologies. http://edumarket.digital

16. S. V. Titova, K. V. Aleksandrova, Theoretical and methodological foundations of the use of electronic educational resources in teaching a foreign language

17. B. Tomlinson, C. Whittaker, Blended Learning in English Language Teaching: Course Design and Implementation

18. I.V. Besperstova, Organization of the educational process using information computer technologies

19. Information and educational environment as a condition for the implementation of the Federal State Educational Standard (2011)

20. Strategy for the development of the information society in the Russian Federation of February 7, 2008 N Pr-212

21. N. A. Kobzeva, Yaroslavl Pedagogical Bulletin, Psychological and Pedagogical Sciences 4(2), 192 (2012)

22. S.V. Titova, Design principles and structure of the course web program

23. I.N. Semenova, A.A. Slepukhin, Methodology of Information Educational Technology Use: Textbook (2013)

24. H.H. Shamanova, E.M. Vishnevskaya, Problems of modern teacher education 62-4, 244 (2019)

25. N.V. Gorokhova, Philological Sciences. Questions of theory and practice 5(47), 81 (2015) 